Post-war changes in the influence of social structure on Australian voting: the 'decline of social cleavages' revisited

\author{
DAVID CHARNOCK \\ Faculty of Media, Society and Culture, \\ Curtin University, \\ GPO Box U1987, \\ Perth WA 6845.
}

Email: d.m.charnock@curtin.edu.au 


\title{
Post-war changes in the influence of social structure on Australian voting: the 'decline of social cleavages' revisited
}

\author{
Abstract \\ Franklin, Mackie and Valen's 1992 book on Electoral Change drew on evidence taken \\ from a small number of surveys in each included country (including Australia) during the \\ mid-1960s to 1990 to derive some general conclusions about the historical decline of \\ cleavage politics. In this article, I make some methodological improvements and also \\ considerably chronologically extend the analyses for Australia, to cover the whole of the \\ post-war period. The results show that some of the previous conclusions are incorrect and \\ that although there has been a decline in the strength of association between social \\ structural variables and voting for the ALP over the post-war period, the decline has not \\ been a smooth one and predominantly occurred in the earlier part of the period. I also \\ discuss the results in the context of broader international debates about the impact of \\ social changes on voting.
}




\section{Post-war changes in the influence of social structure on Australian voting: the 'decline of social cleavages' revisited}

\section{Introduction}

One of the most substantial empirical contributions to the international literature on historical changes in the relationship between social cleavages and political alignments was the multi-authored book Franklin, Mackie and Valen (1992). This was sponsored by the Committee on Political Sociology of the International Political Science Association and the International Sociological Association, and drew on longitudinal analyses of survey data (generally covering a period from about the mid-1960s to 1990) from sixteen western countries (including Australia) in an attempt to draw conclusions that would have cross-national validity.

One of the main conclusions of the authors (discussed in chapters 19 and 20 of their book) was essentially that there is a developmental process that explains the decline of social cleavages in relation to voting. This process started later in some countries than in others and, in the case of Australia, they argued that it was an "early decline" country (i.e. the process had begun before the 1960s).

It is not completely clear what they project for the then-future (i.e. post 1990) nature and extent of the relationship between social groups and voting, but there seems to be a suggestion in places that at least several of the authors believed there would be no ongoing role for social cleavages (e.g. "our observations suggest that post-industrial society may no longer even have the capacity to socialize people into loyalties towards social groups" (van der Eijk et al 1992 : 416)). The chapter on Australia was authored by Ian McAllister, who concluded that "There seems little doubt that the decline in the electoral importance of class has been substantial" (but occurred mainly between 1967 and 1979) (1992a: 72), but also that "Class and its concomitants ... remain the main social bases of the political parties" (1992a: 81). 
The Franklin, Mackie and Valen (1992) arguments were, of course, reflective of a quite widespread belief (e.g. Clark et al 1993; Inglehart 1977, 1997) that social cleavages, of which class was most often the most significant, had already had (and would continue to have) decreasing political significance, with consequences such as the growth of new parties. Their evidence is quoted extensively and approvingly by Pakulski and Waters (1996: 136) in their well-known book The Death of Class: "The importance of this study rests not only on its impressive comparative scope, but also on a sophisticated methodology that uses regression techniques to reveal electoral trends."

The question has generated widespread debate, including over the often associated argument that non-class based issues have become more significant for voting as the framing of political interests has changed. Matters related to methodology have been an important part of the empirical side of the discussion. The edited collection of chapters (mainly consisting of detailed case studies of individual countries, not including Australia $^{1}$ ) that forms Evans (1999) is an extensive recent one devoted to the 'decline of class' argument specifically. On the basis of the evidence presented there, the editor concludes (Evans 1999: 333): “....generic theories of the decline of class voting and class politics in industrialized societies are empirically unsupported, as by extension are those theories which claim that all social-structural bases to politics are in decline."

Clearly, the effect of using varying methods can be substantial and a detailed reexamination of the Australian evidence is required before we can be confident about previous conclusions. One significant concern in this regard about the Franklin et al project results from the fact that, in order to maximize the degree of cross-national comparability, several compromises were made. One of these was that the measurement level used for the social structure variables studied was very coarse; the core variables are all measured simply as dichotomies. This necessarily resulted in a definite understatement of the strength of association between social structure and (left) vote (the dependent variable selected for the project). The authors themselves acknowledged this and, in fact, van der Eijk and Niemoller (1992: 273-4) found a general increase in the 
value of r-squared for the Netherlands of 3-8 percentage points when using polytomies in place of the dichotomies.

Also, in general there were only 3 time points used in each country, largely determined by the availability of suitable survey data, so the assessment of patterns (in specific countries at least) is potentially unreliable: the inclusion of a single unrepresentative or unusual year can markedly change the apparent pattern. In the case of Australia, the years used were 1967, 1979 and 1987 (two of Aitkin's surveys and the first Australian Election Study, respectively). The assessment of Australia as an "early decline" country seems somewhat inconsistent with the conclusion of Jones and McAllister (1989) that there was no decline in class voting in Australia until after the middle of the 1960s, although a partial explanation for this might lie in a reduction in religious denomination effects from the mid-1950s onwards. Another possible explanation is that Jones and McAllister use more detailed sets of categories than simple dichotomies to measure their social structure variables. Again, though, Jones and McAllister use only 3 time periods (late 1940s/ mid1960s/ early1980s) in their analyses and, as noted above, this makes the assessment of patterns potentially unreliable.

A quite similar analysis to McAllister (1992a) appears in McAllister (1992b: 169), although with the 1990 AES replacing the 1987 AES. A possibly significant difference between the two is that the McAllister (1992b) analysis includes only ALP and Coalition voters, whereas the other analysis had also included voters for the DLP and the Australian Democrats, which one would expect would dilute the apparent strength of the relationship between social cleavages and voting. His overall conclusion, however, remained the same viz. that there had been a decrease in the significance for voting of social structure, and a concomitant increase in the importance of issue voting.

As far as case studies of individual countries are concerned, Australia has the advantage of being one of the earliest countries to begin ongoing opinion polling and hence is one of only a fairly small number for which analyses can be extended much further backwards in time. Both Alford (1963) and Kemp (1978) (who also uses the 'post-industrial society' 
theme in his argument about the decline of class voting) made use of these early polls. The critique of Kemp's work in Jones and McAllister (1989) also draws on some of them, as does Goot's (1994) more general critique of the Australian debate.

The most recent extensive analysis is in Weakliem and Western (1999). They concluded that there had been a post-WWII decline in class voting and concurred with both Jones and McAllister and Goot that the decline had not occurred steadily over the period. This is in contrast to Kemp's description of a more steady decline. However, Goot had also argued that the timing of declines in class voting was connected to political factors; in contrast, Weakliem and Western concluded that they could find no obvious such connection.

None of this Australian research both covers the whole of the post-war period and also analyses a full set of social structure variables such as those considered in the Franklin, Mackie and Valen (1992) project; they either deal only with class voting specifically (Kemp; Goot; Weakliem and Western), or analyse only a limited number of time points (Jones and McAllister; McAllister). Since the detailed work on the 1996 election reported in Charnock (1997) shows that even in an election where traditional (or even extended) measures of occupational class had only weak associations with voting, other social structural variables remained significant, consideration of a broader set of variables over an extended period might well provide different conclusions.

This is not merely a question of improving the description of patterns of change, it also should help to explain them. The potential for different political consequences makes this kind of question a matter of some practical importance. For example, as the extent of class voting as measured by occupational class has diminished, has this been replaced (partially, at least) as an influence on voting by other social structural aspects (such as the private/government sector division) or has voting begun to revolve more around other things, such as the sort of distinctions around values that authors such as Inglehart postulate. 
If the latter were true, then a subsequent important question to investigate would be that of the nature of the relationship between such values, voting and social structural location. It is not possible to address this here, but it is worth noting that the (often associated) idea that any new value dimension (such as one based on post-materialist or modern values) necessarily either replaces a left-right one or crosscuts it completely independently is not supported by more recent research, that instead suggests that the two dimensions are fairly strongly correlated with each other (see Kitschelt's $(1994,1995)$ work on Europe, and Charnock and Ellis $(2003,2004)$ for Australia).

Both chronological and methodological extensions of the previous research in the area have the potential to offer valuable insights and so I will present here the results of doing the following:

(i) examining the full post-WWII period, election by election, so that there is no difficulty disentangling isolated or temporary effects from long-term ones;

(ii) using more complex measurements of social structure than those in McAllister (1992a, 1992b), in order to avoid under-estimating the strength of the association between social structure and voting;

\section{Data and Methods}

Survey data, publicly available through the Australian Social Science Data Archives (ASSDA), on the broader set of social structure variables are not completely comparable for the entire post-war period. There is enough continuity in the earlier period to use Morgan Gallup Polls, but later Australian Gallup Polls conducted by McNair Anderson asked respondents about a more limited range of background characteristics (including omitting religion). The ASSDA does, however, hold the data for Age Polls between 1972 and 1981. The first of the large-scale general academic surveys was conducted by Aitkin in 1967 (with a second wave in 1969), but the next was not until Aitkin's Australian Political Attitudes Survey in 1979. The National Social Science Surveys began in 1984 and the series of Australian Election Studies commenced in 1987. 
An element of discontinuity is therefore inevitable, because there are some differences in definitions of categories and sometimes in the variables available. This could be a serious problem if we were assessing changes by examining estimated coefficients for individual categories, but the nature of the main measure used (an r-squared measure, for comparability with the approach used in Franklin, Mackie and Valen (1992)) is such that the impact of category differences is likely to be small. Even occasional differences in the availability of particular social structure variables can be approximately allowed for, though this is necessarily more speculative. As far as possible, polls were selected that had been conducted shortly before or shortly after an election date; analyses showed that the two gave similar results for the r-squared measure used.

The analytical technique used is bivariate logistic regression for ALP vote v Coalition vote. This is consistent with the approach used in Jones and McAllister (1989) and McAllister (1992b), but differs from that used in McAllister (1992a), which uses ALP v [Coalition + DLP + Australian Democrats]. This second approach would almost certainly have the effect of diluting the apparent impact of social structure, especially at times when voters for the Australian Democrats were closer to the ALP than to the Coalition. When necessary, however, I will also comment on the impact on my results of including DLP and Australian Democrats voters.

The measure focused upon in the Franklin, Mackie and Valen book was an r-squared value, representing the percentage of variance in ALP voting explained by the social structure variables. The measure used here is an analogous one for bivariate logistic regressions (the McKelvey and Zavoina r-squared coefficient). ${ }^{3}$ Snijders and Bosker (1999) describe the multilevel equivalent.

The core variables used in the Franklin, Mackie and Valen project (in the McAllister 1992a chapter about Australia) were as follows:

Manual occupation 
Trade Union member

Minimum education

Urban resident

Sex

NSW resident

Aged below 45 years

Self-identified working class

Frequent religious attendance

Some analyses (in the so-called 'expanded set' of variables) also included Religious Denomination (categorized as Catholic/No religion/Other (the excluded, reference category, effectively Protestant)) and others (in the 'country-specific' set of variables) also added Country of Birth (categorized as S. European/ E. European/ Other (the excluded, reference category, effectively Australian and British)).

Jones and McAllister (1989) base their analyses on the following variables:

Age (3 categories)

Sex

Large city resident

Religion (4 categories)

Occupational Class (5 categories)

Phone ownership

Car ownership

My analyses maintain a close degree of comparability with the variables incorporated (but, as in Jones and McAllister (1989), measured in more detailed sets of categories than the dichotomies used in McAllister (1992a)). I added State of Residence to the variables used in Jones and McAllister and used slightly more categories for each of Age, Religion and Occupational Class. 


\section{Results}

As already mentioned, although the general nature of the social structure variables included is the same, several of those used in my analyses use more categories than those reported in McAllister (1992b: 169). As expected, therefore, making a direct comparison (based on the same data sets) ${ }^{4}$ shows that the more detailed categorization incorporated in my analyses reveals a stronger degree of association of vote with social structure, about 10 percentage points higher in each survey (see Figure 1). This confirms the fact that the methodology used in Franklin, Mackie and Valen (1992) understated the strength of association by significant amounts.

Figure 1:

Variation in ALP voting explained by social structure variables (comparison with McAllister 1992b)

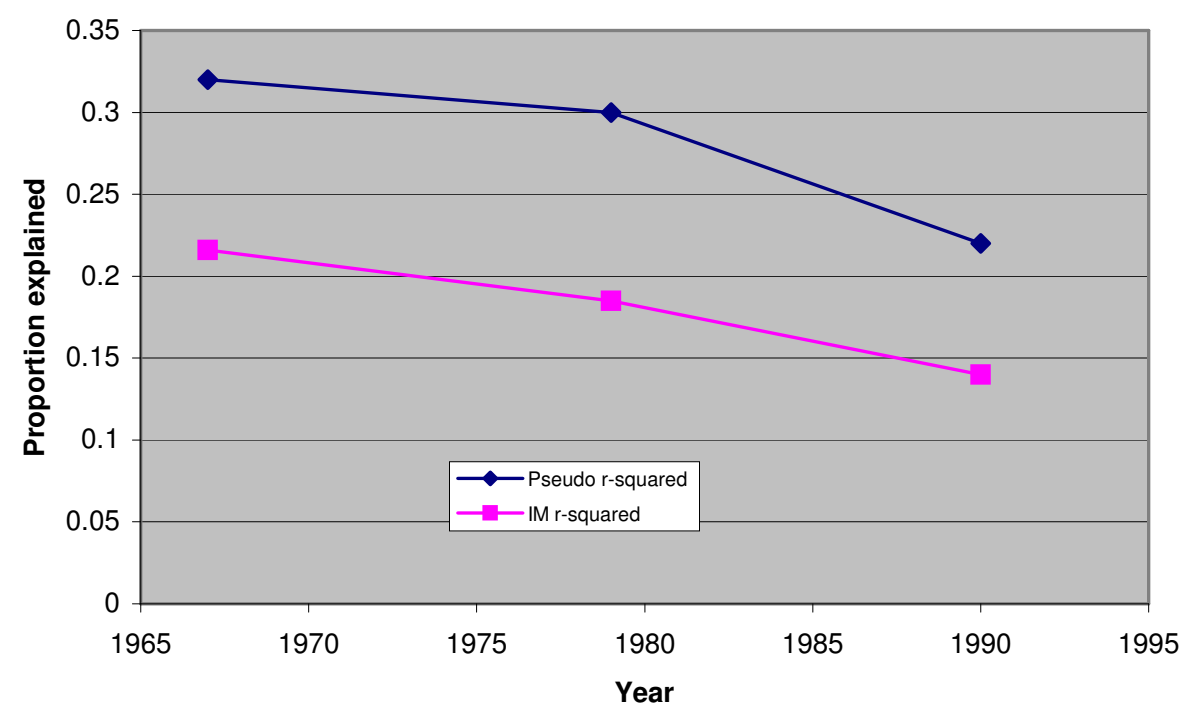

Note: Bottom line based on McAllister (1992b: 169). Top line based on logistic regression analyses of Aitkin's 1967 and 1979 surveys and the 1990 Australian Election Study. Analyses include ALP and Coalition voters.

However, although the levels are different for the two sets of analyses, the pattern over time is essentially unchanged, showing an overall decline between 1967 and 1990, with 
most of this occurring between 1979 and 1990. This might seem to support an interpretation of an ongoing decline in the significance of social structure (as seems to be suggested in Franklin, Mackie and Valen 1992), but when the analyses are extended beyond 1990 a different picture emerges. Figure 2 includes results from all three of Aitkin's surveys and all of the Australian Election Studies from 1987 onwards, as well as the 1984-5 National Social Science Survey.

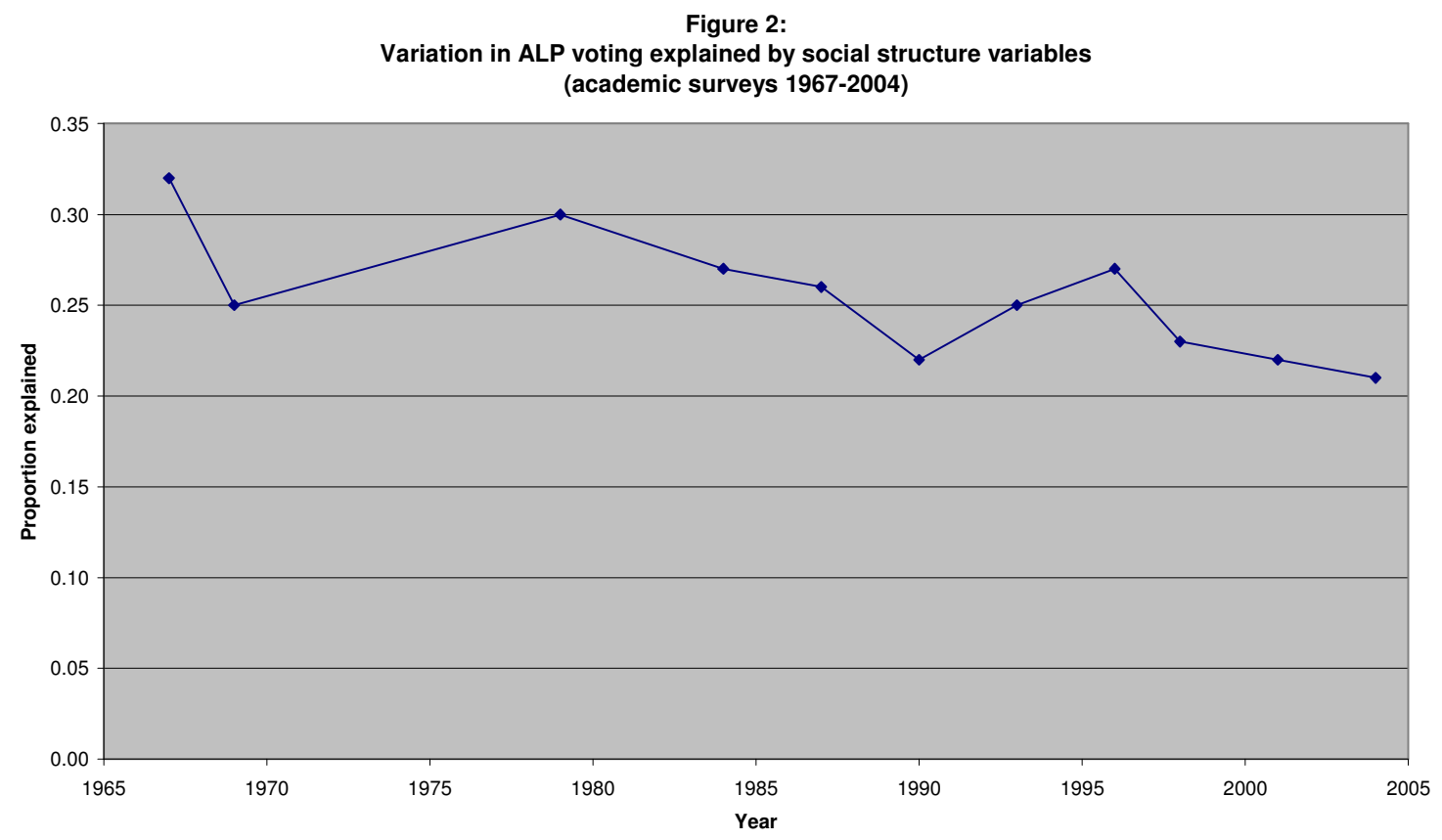

This shows that 1990 was actually a local low point, with subsequent increases in 1993 and 1996, before a drop to around the 1990 level again from 1998 onwards. While the inclusion of the NSSS results makes no difference to the pattern, that of the 1969 second wave of Aitkin's study makes a substantial difference to the likely interpretation because it suggests that there might have been fluctuations not previously evident. Although various possible explanations for these suggest themselves, the lack of other academic surveys through the 1970s makes it very difficult to choose an appropriate one at this stage. I will return to this period later on. 
Clearly, examining this chronological extension beyond 1990 must modify our understanding of the relationship between social structure and voting because it does not confirm the pattern of continued decline that was suggested by the results in McAllister (1992a, 1992b). Rather, it seems to suggest an approximate leveling out at the lower level, combined with occasional increases.

Is it also the case that a different pattern is observed if we extend the period in the opposite direction, from the mid-1960s back to the end of WWII? In light of the discontinuity between the early Morgan Gallup Polls and the later academic surveys, at this stage I will proceed by considering the Gallup Poll results by themselves and will leave a discussion of the complete post-war period until later.

Figure 3:

Variation in ALP voting explained by social structure variables

(Gallup Polls 1946-66)

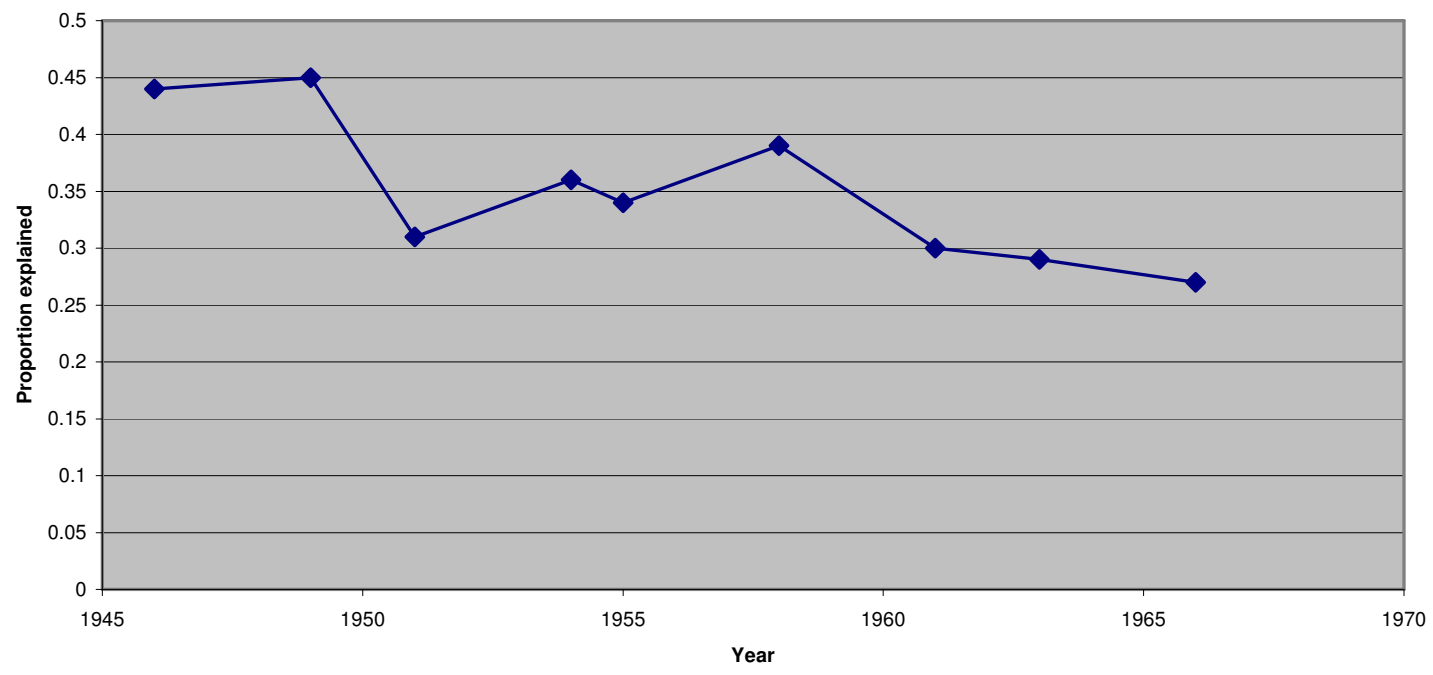

The results are presented in Figure 3 and show a quite substantial drop between the beginning and the end of the two decades long period in the proportion of variation in ALP voting explained by the social structure variables (from around $45 \%$ to just over 
$25 \%)$. As already seen in the later period, however, the pattern of change is not a smooth one. First, and perhaps most notably, there clearly appears to be a significant difference between the pre- and post-1950 periods, with a very large drop between 1949 and 1951 . Second, the results from the 1950s show some fluctuations, though followed by consecutive decreases through to 1966.

There is enough internal comparability within each of the two periods, that have been dealt with separately up to now, to draw reasonably secure conclusions about patterns of change during the respective periods. It would also be very valuable both to 'splice together' these two periods and also to fill in some of the missing detail from the 1970s. There are, however, some difficulties in doing this by drawing on data from Age Polls, so patterns should be treated with a little caution when assessing fine detail, though broad outlines are not as susceptible.

One source of difficulty is that almost none of the Gallup Polls gathered information about trade union membership and religious attendance (nor did the Age Polls on trade union membership), whereas all of the academic surveys did so. Another problem is that information on employment sector (government, private, self-employed) was not collected in either of Aitkin's 1967 and 1969 surveys, nor in the Gallup and Age Polls (although their occupational class measures do incorporate an element of the selfemployed category), but it was included in the academic surveys from 1979 onwards.

One strategy for dealing with the difficulties of comparability would be to simply omit all three of these variables from all analyses, including those in the academic surveys from 1979 onwards. However, since all three have potentially important associations with voting, such a procrustean solution does not seem sensible to me. I think a better approach, at least for the large gap in the1970s between Aitkin's surveys, is to hypothetically incorporate them where necessary by assuming that their additional contribution at an election to the r-squared measure would be equal to the average contribution at succeeding elections for which relevant data were collected (and hence where their contribution is actually known). This obviously has something of a 
'smoothing effect' on the pattern of change, but should give a better indication of the overall levels of influence of social structure on voting.

Suitable available data are so remote from the Gallup Polls between 1946 and 1966, however, that it does not seem desirable to do this in their case and I have chosen to leave the results for them as they appeared previously in Figure $3^{5}$.

Figure 4:

Variation in ALP voting explained by social structure variables 1946-2004 (using imputed averages for omitted variables 1969-80)

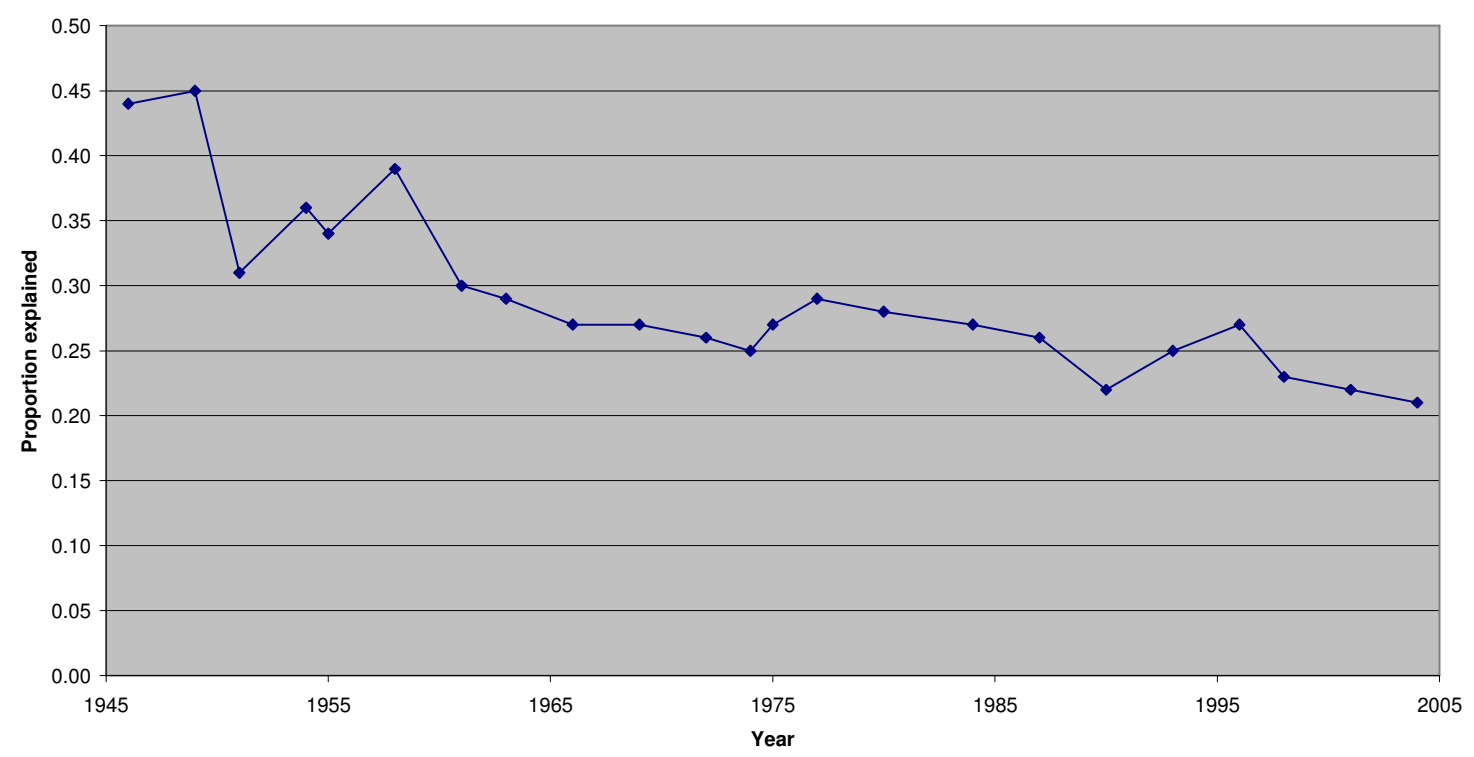

Adopting this approach gives the results seen in Figure 4. This is obviously a picture of overall decrease in the extent to which ALP voting has been related to social structure variables, but is not the kind of smooth decline that would be expected from some arguments. The short-term fluctuations visible in my results support Goot's point about the need to consider contemporary political factors and, if anything, the period when Gough Whitlam was leader of the ALP appears as a relative low point in the influence of social structure. Given the nature of the debates within the ALP about the need to expand beyond traditional social bases of support in order to win office, this is an interesting feature. However, as mentioned earlier, the problems with data comparability make drawing such a detailed conclusion a little insecure. 
Nevertheless, I think we can be quite confident about the broader conclusion that the evidence of Figure 4 shows only relatively small changes between the early 1960s and the late 1980s and no indication that since then the association of these social structure variables with voting has been fading away towards complete insignificance ${ }^{6}$.

Alternative methods of taking account of non-major party voters can make some difference to the results and the size of such differences also varies somewhat over time. With the main exception of 1958, the effect of including DLP voters is small, but including Australian Democrats voters has more influence and the size of the decrease in r-squared also varies more, being as small as one percentage point in 1993 but as large as five points in 1990 and four points in Aitkin's 1979 survey. In consequence the details of particular fluctuations are sometimes different, but the conclusion that the association of these social structure variables with voting has not been fading away towards complete insignificance remains true.

\section{Discussion}

A simple overall description of this pattern of change subdivides the postwar period into three or four eras. The first appears to have ended in about 1950 and in the context of this study was characterized by a high degree of association between vote and a fairly small set of social structural variables, mainly reflecting socio-economic background (particularly occupational class), but with religion also having a notable effect. At this time, about 45 per cent of variation in ALP voting (vis-a-vis the coalition parties) was associated with these variables.

The second period seems to have roughly coincided with the 1950s. The degree of association between social structure and vote during this period, although lower than pre1950, remained quite high but fluctuated more often and in a wider range (between 31 and 39 per cent) than in subsequent periods of the same length. Both religion and socioeconomic background continued to be important ${ }^{7}$, but the fluctuations were generally associated with occupational class. 
The post-1960 period could possibly be described as a single era, but I think it is preferable for it to be divided into two, the first section covering approximately the three decades beginning in 1960 and the second starting shortly before 1990. In the first, the strength of association between social structure and vote (generally in the range from 25 to 30 per cent of variation explained) was lower than in the $1950 \mathrm{~s}$, but there are few short-term fluctuations and changes are generally fairly slow and smooth. In general, the influence of religion was further reduced during this period (the inclusion of DLP and Democrats voters does not alter this conclusion), as also was that of occupational class.

The 1990-2004 period, although much shorter than the previous section, shows somewhat larger fluctuations and, on average, a further reduced strength of association, down to 22 per cent of variation explained in 1990 and between 21 and 23 per cent from 1998 to 2004. Further, for most of this period increases in minor party voting meant that this association was applicable to only $80-85$ per cent of the electorate compared to amounts that were usually over 90 per cent prior to 1990. By this time, no single social structure variable dominates in the way that occupational class did in the early part of the post-war period, and although fluctuations are mainly associated with employment-related variables ${ }^{8}$, the strength of association between vote and religion also shows some variations. Interestingly, the 1993 and 1996 elections, which were those at which the strength of association increased, were the only two in this period where the major party vote exceeded 85 per cent. This suggests that aspects of the electoral system in the House of Representatives that discourage large increases in the extent of voting for minor parties help to underpin the association between social structure and vote.

Although my analyses are based on a group of social structure variables and his are based only on the occupational class variable, these features are quite similar to those identified by Goot (1994: 162-167) in his examination of odds ratios up to 1993, and so seem to provide support for a good deal of his political interpretations of the changes. However, given that one of the social structure variables is religious denomination, the similarity of the overall pattern to that for occupational class alone might appear hard to understand for the elections around and following the ALP split in the mid-1950s and the subsequent 
formation of the DLP (which, of course, had a significant influence on the impact of religious denomination on vote).

The fact that only ALP and Coalition voters are included in the analyses is part of the explanation for this; if DLP voters are also included (and effectively incorporated with Coalition voters in the logistic regressions for ALP vote) then the pattern alters a little, with the peak in 1958 not being quite as pronounced (because the r-squared value is reduced most in 1958, by 0.04).

Examination of the detailed differences, however, shows that the major explanation is that short-term fluctuations in this period were mainly associated with occupational class, while the smoother decline from the late 1950s to the mid-1960s occurred essentially simultaneously in both occupational class and religious denomination. The former aspect supports Goot's argument that specific political factors are important, while the latter might be seen to support the Franklin, Mackie and Valen argument about longer-term changes in the significance of social structure more generally.

In terms of the implications of these results for our interpretation of underlying processes, one immediate conclusion to draw from the short-term fluctuations is that contemporary political factors cannot be ignored in assessing the way in which changes in the strength of association between social structure and voting have occurred. It is certainly not adequate to describe the overall decline over the period as a whole as a simple and smooth reaction to (or consequence of) social change, as many authors have argued both internationally and for Australia specifically. From 1960 onwards, at least, my findings are more in line with the arguments in several of the chapters in Evans (1999), where national circumstances (including the structure of the party system) are argued to be necessarily important.

On the other hand, in the broad cross-national context considered by Franklin, Mackie and Valen (1992), my findings about the pre-1960 post-war period do appear to support their inclusion of Australia in the group of 'early decline' countries. While they do not 
explicitly address the question of why Australia might fall into that category, they argue in general that "....declining cleavage politics can be regarded as a consequence of the successful resolution by political systems of deep-seated conflicts of social interests" (van der Eijk et al 1992: 423). This suggests an explanation that draws on Australia's relative economic prosperity and stability in the first part of the post-war period, together with Menzies' willingness to use some government intervention and maintain aspects of a welfare state.

An alternative possible explanation could be based on the argument offered by Scalmer (1997: 401, 415), indicating that consideration of a political explanation involving changes within the ALP is necessary. He argues that the transformation of the ALP during the 1950s,

“....shedding its pursuit of nationalization, its rhetorical commitment to socialism, and many of its democratic ties to the organized working class .... was not caused by broad movements in the economy, by the rise of the affluent worker, nor by the decline of working-class consciousness. The shift was caused by political struggles, and was in no sense inevitable."

This argument emphasizes the significance of the institutional framework as well as the social one and is quite consistent with those in Evans (1999) arguing the need to consider national circumstances. The timing also coincides well with the chronological patterns in my results, although it obviously has no bearing on my finding of a large decrease between the pre-and post-1950 eras.

\section{Conclusion}

These analyses provide chronological extensions (both forwards and backwards) to previous comparable research, give more detail about the period covered by earlier researchers and explore the impact of incorporating some methodological improvements. 
The findings are consequently more firmly based than previous ones, and also help in choosing between some previously argued positions about patterns of change in the relationship between aspects of social structure and voting.

The broad pattern over the post-war period is one of an overall decrease in the influence of social structure on ALP voting. However, it is a rather episodic decline modulated by contemporary political factors. The largest decline was in the period before 1960, and from then until about 1990 there was a fairly stable aggregate impact (in some of the international literature, this would probably be described as 'trendless fluctuation'). In this sense, in relation to previous Australian authors, my results provide support both for some of Goot's arguments (about the need to take political factors into account) and also for McAllister's about the existence of a decline in the significance of social structure for voting.

With regard to this latter, though, the use of dichotomous measures means that McAllister's work necessarily understated the degree of association between social structure and voting, by an average of about 10 percentage points. The extension to 2004 presented here also demonstrates that the pattern of ongoing decline that was suggested by his analyses up to 1990 has not been borne out, with recent levels being similar to those in 1990. Moreover, the finding that those recent elections that had higher levels of minor party voting were also those with lower levels of association between social structure and voting suggests that the electoral framework will, in any event, help to provide some sort of lower limit to the extent to which the association is likely to weaken. 


\section{References}

Alford, R. 1963. Party and Society: The Anglo-American Democracies. Chicago: Rand McNally.

Charnock, D. 1997. 'Class and voting in the 1996 Australian federal election.' Electoral Studies 16: 281-300.

Charnock, D. 1996. 'National uniformity, and state and local effects on Australian voting: A multilevel approach.' Australian Journal of Political Science 31 (1): 51-65.

Charnock, D. and P. Ellis. 2004. 'Postmaterialism and postmodernization in Australian electoral politics.' Electoral Studies 23: 45-72.

Charnock, D. and P. Ellis. 2003. 'The structure of the Australian party system and its strategic consequences.' Australian Journal of Political Science 38 (3): 423-43.

Clark, T.N., S.M. Lipset and M. Rempel. 1993. 'The declining political significance of social class.' International Sociology 8(3): 293-316.

DeMaris, A. 2002. 'Explained variance in logistic regression: A Monte Carlo study of proposed measures.' Sociological Methods and Research 31 (1): 27-74.

Evans, G. (ed.). 1999. The End of Class Politics? Oxford: Oxford University Press.

Franklin, M., T. Mackie and H. Valen. 1992. Electoral change: Responses to evolving social and attitudinal structures in western countries. Cambridge: Cambridge University Press.

Goot, M. 1994. 'Class voting, issue voting and electoral volatility.' In Developments in Australian Politics eds. J. Brett, J. Gillespie and M. Goot. South Melbourne: Macmillan.

Inglehart, R. 1997. Modernization and Postmodernization: Cultural, Economic and Political Change in 43 Societies. Princeton, NJ: Princeton University Press.

Inglehart, R. 1977. The Silent Revolution: changing values and political styles. Princeton, NJ: Princeton University Press.

Jones, F.L. and I. McAllister. 1989. 'The changing structural base of Australian politics since 1946.' Politics 24 (1): 7-17. 
Jones, K., R.J. Johnston and C.J. Pattie. 1992. 'People, places and regions: exploring the use of multi-level modelling in the analysis of electoral data.' British Journal of Political Science 22 (2): 343-80.

Kemp, D. 1978. Society and Electoral Behaviour in Australia. St Lucia: University of Queensland Press.

Kitschelt, H. 1995. The radical right in Western Europe: a comparative analysis. Ann Arbor: University of Michigan Press.

Kitschelt, H. 1994. TheTransformation of European Social Democracy. Cambridge: Cambridge University Press.

McAllister, I. 1992a. 'Australia.' In Electoral change: Responses to evolving social and attitudinal structures in western countries, M. Franklin, T. Mackie and H. Valen. Cambridge: Cambridge University Press.

McAllister, I. 1992b. Political Behaviour: Citizens, Parties and Elites in Australia. Melbourne: Longman Cheshire.

Nieuwbeerta, P. and N.D. De Graaf. 1999. 'Traditional Class Voting in Twenty Postwar Societies.' In The End of Class Politics? G. Evans (ed.). Oxford: Oxford University Press.

Pakulski, J. and M. Waters. 1996. The Death of Class. London: Sage.

Scalmer, S. 1997. 'The Affluent Worker or the Divided Party? Explaining the Transformation of the ALP in the 1950s.' Australian Journal of Political Science 32 (3): 401-18.

Snijders, T.A.B. and R.J. Bosker. 1999. Multilevel Analysis: An Introduction to Basic and Advanced Multilevel Modeling. Thousand Oaks, CA: Sage.

Van der Eijk, C., M. Franklin, T. Mackie and H. Valen. 1992. 'Cleavages, conflict resolution and democracy.' In Electoral change: Responses to evolving social and attitudinal structures in western countries, M. Franklin, T. Mackie and H. Valen. Cambridge: Cambridge University Press.

Van der Eijk and K. Niemoller. 1992. 'The Netherlands.' In Electoral change: Responses to evolving social and attitudinal structures in western countries, M. Franklin, T. Mackie and H. Valen. Cambridge: Cambridge University Press. 
Weakliem, D.L. and M. Western. 1999. 'Class voting, social change and the left in Australia, 1943-96.' British Journal of Sociology 50 (4): 609-30.

Western, M. and B. Tranter. 2001. 'Postmaterialist and economic voting in Australia, 1990-98.' Australian Journal of Political Science 36 (3): 439-58. 


\section{NOTES}

${ }^{1}$ Although Nieuwbeerta and De Graaf (1999) do include Australia in their comparative analysis of class voting in 20 countries, they include the DLP as a left-wing party, in contrast to analyses by other researchers.

${ }^{2}$ In addition to the constraints on the project design mentioned above, earlier researchers were also unable to take much account of the technical problems that might arise from the cluster sampling methods typically used in the surveys. In principle, use of the more recently developed multilevel techniques (e.g. Jones et al 1992; Charnock 1996) can overcome these problems, when suitable detail about sample designs is available. In practice, however, little difference resulted from using these techniques (see note 6).

3 DeMaris (2002) indicates this is the best such one for a situation such as this, where the supporters of the major parties can be regarded as primarily differentiated on a single underlying dimension (cf. Charnock and Ellis (2003; 2004) and Western and Tranter (2001)).

${ }^{4}$ In both cases, I have excluded the Parental Socialisation measures (because they were not included in the Franklin, Mackie and Valen study).

${ }^{5}$ On two occasions where data on union membership was collected in the early Gallup Polls, its extra contribution to r-squared was only 2 percentage points in both cases, an amount that is generally similar to that from 1979 onwards.

${ }^{6}$ When multilevel analyses were carried out, the effect was to reduce the r-squared values by only small amounts (generally two percentage points) and, since the reduction was almost the same for each survey, the patterns of change over time are unaltered.

${ }^{7}$ This conclusion needs to be slightly modified if account is also taken of DLP voters; in that case, the effect of religion is reduced (and hence so is the overall degree of association between social structure and vote, at its largest by 4 percentage points in 1958).

${ }^{8}$ See Charnock (1997) for a detailed analysis of this in relation to the 1996 election.

\section{Acknowledgements}

I would like to thank Kay Fisher and Peter Ellis for their research assistance and the Journal's reviewers for their constructive comments on an earlier draft. This research was supported by Australian Research Council Large Grant no. A79938063. 